\title{
Angiomas of the spinal cord: review of the pathogenesis, clinical features, and results of surgery
}

\author{
VA L E N T I N L O G U E \\ From the Gough-Cooper Department of Neurological Surgery, National Hospitals for Nervous \\ Diseases, Queen Square and Maida Vale, London
}

SUMMARY Twenty-four patients with angiomas of the thoraco-lumbo-sacral region of the spinal cord, which characteristically occur in elderly men and are situated on the dorsum of the cord, were subjected to surgery after diagnosis by selective arteriography. It is suggested that in this variety of angioma the operation produced its effect by eliminating the raised pressure in the venous and capillary vessels within the spinal cord. There was no evidence of an arterial "steal." In all cases, followed up for a mean of five years, progression of neurological symptoms was arrested but, apart from motor disability and pain, any improvement among this already seriously disabled group was small. Diagnosis in the early stages is difficult but the history of mechanical factors exacerbating the symptoms and which occur in the majority of patients should suggest the presence of such a lesion and indicate the need for myelography. Any improvement in results can only come from greater awareness of the condition leading to earlier diagnosis and operation.

The natural history of angiomas of the spinal cord with its sinister implications for cord function whereby, for example, $19 \%$ of patients develop severe disability of gait within six months of onset of symptoms, and $50 \%$ are virtually chairbound within three years, is now widely known (Aminoff and Logue, 1974a). Surgical treatment of the condition in the hope of retarding or reversing the natural downhill trend is a relatively recent innovation. Although a good deal has been written about it the precise degree of improvement that may ensue, and whether this relates to all or only some of the neurological modalities involved, has not yet emerged, nor has the outcome with regard to permanence.

Krayenbuhl et al. (1969) have made a significant contribution towards this but most of the cases in their series were not subjected to selective arteriography. More recently, the experience of Djindjian and his colleagues, with a series of 150 cases covering all varieties of cord angiomas, has clarified the influence of surgery and embolisation on them, but only as far as motor function is concerned (Djindjian, M., 1976).

Address for reprint requests: V. Logue, 16 Rowan Road, London W6. Accepted 12 June 1978
It is my purpose in this paper to analyse in greater detail the outcome of operative intervention in a consecutive series of 24 cases of spinal angiomas all delineated by selective arteriography, with regard to locomotion, sphincter function, sensation, and pain, together with an assessment of the morbidity arising from surgery and arteriography. I will also discuss the change in surgical principles brought about by the recent demonstration that some of the thoracolumbar arteriovenous malformations (AVMs) are situated extradurally and not on the spinal cord (Kendall and Logue, 1977).

The cases to be described are examples of that group of AVMs which present primarily to the neurologist and the specialised neurological department. They show the picture of progressive and relentless neurological deterioration tending towards spinal cord transection, and, in the early stages, may give rise to considerable difficulty in diagnosis. Intraspinal haemorrhage is uncommon. These lesions are virtually confined to the thoracolumbo-sacral zone, usually situated on the posterior aspect of the spinal cord, and occur mainly in elderly men. They are the easiest of all cord angiomas to treat surgically.

The gross anatomy of the angiomatous blood 
vessels in this thoracolumbar group and the course they take deviates markedly from the normal pattern. In $90 \%$ of the cases the "feeding" arterialised blood vessel is solitary and pierces the theca in the vicinity of a nerve root sleeve, but usually 2-3 $\mathrm{mm}$ caudal and a similar distance anterior or posterior to it. From here the vessel does not run with the nerve but takes a more transverse course to reach, in $80 \%$ of the cases, the dorsum of the cord where the characteristic tortuous thin-walled anastomosing blood vessels of varying calibre wander upwards or downwards, sometimes in both directions for a long distance. When these trunks are dissected off the spinal cord during surgery a number of small perforating vessels are seen to run from them directly into the cord substance. In a longstanding case transverse sections of the spinal cord may show the ramification within it of these small vessels and their branches which, although dilated, do not compare in size with those on the surface whose walls are unsupported in the subarachnoid space (Fig. 1).

In some cases (one in this series) these intramedullary vessels do in fact dilate in comparable fashion to the superficial ones.

In a previous publication we suggested (Aminoff et al., 1974) that the commonly held view of an arterial "steal" being responsible for ischaemic damage to the nerve fibres was incorrect, and a number of reasons were adduced in support of the opinion that prolonged raised venous pressure in the veins and capillaries within the substance of the spinal cord was the cause of the neurological lesion. Since then two further observations which tend to confirm this view have been made. The first derives from the study of a patient (case 21) with a myelographically proven thoraco-lumbosacral angioma. At arteriography all the blood vessels normally capable of supplying the spinal cord were delineated selectively. This revealed an angioma filling from the left lateral sacral artery and lying in the hollow of the sacrum below the level of the termination of the dural sac. This AVM provided no arterial supply to the cord but gave off a single large vessel which pierced the tip of the theca to ascend in the situation of the filum terminale to the conus medullaris and then ran on the spinal cord up to the $T$ 5/6 vertebral level and possibly beyond (Fig. 2). Surgical exploration demonstrated that the large vessel contained venous blood flowing in the cranial direction, and microscopical section of its wall confirmed it to be a vein (Fig. 3).

The only explanation for the cord damage in this patient was that of raised venous pressure in the intramedullary vessels. Similar cases have been

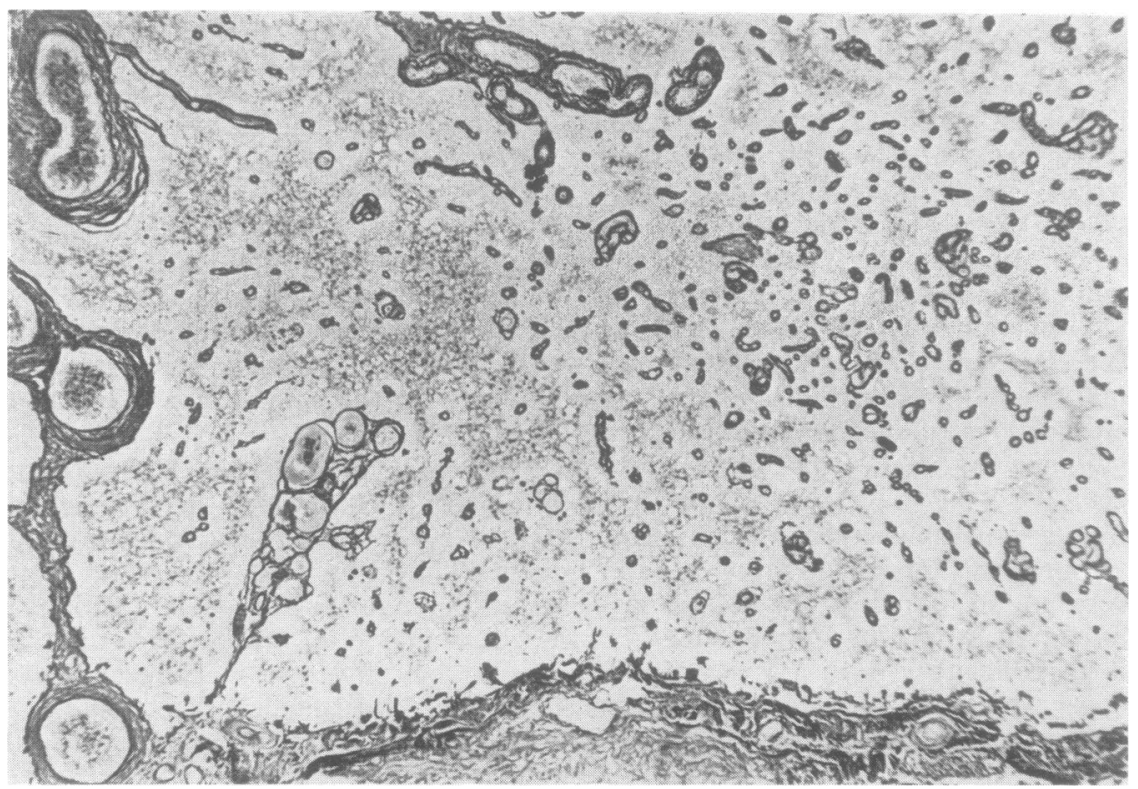

Fig. 1 Transverse section of the anterior part of the spinal cord at the $T 7$ segment in a man of 47 years, with a 12 year history and totally paraplegic for four years. Many dilated vessels are seen within the cord substance. Larger vessels are visible in the antcrior sulcus, to the left, and in the thickened meninges. 


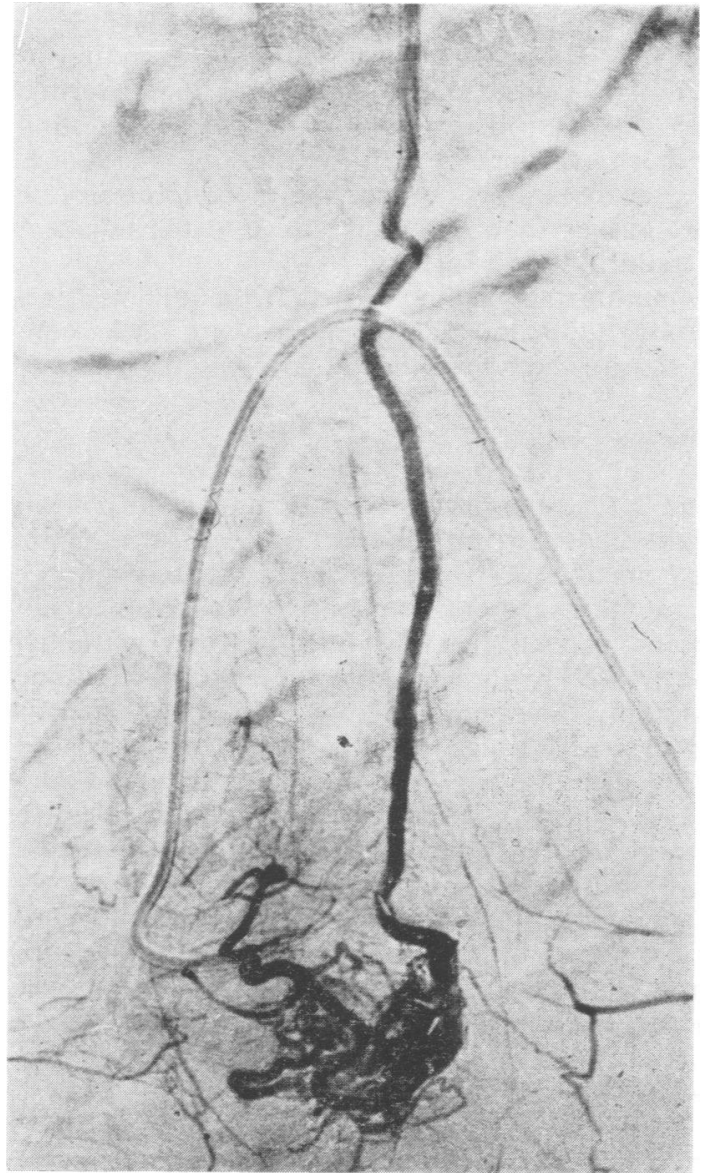

Fig. 2 Subtracted radiograph of the left internal iliac artery (the film has been transposed), the catleter is in the lateral sacral branch filling the angioma. An emergent vein runs upwards in the midline to p:erce the theca and accompany the filum terminale to reach the spinal cord and ascend on it.

reported by Stein et al. (1972) and Heindel et al. (1975).

The second observation concerns those cases with an extradurally sited AVM from which the sole communication with the cord vasculature is by means of its emergent theca-piercing and histologically proven vein. There is no connection between the intercostal artery supplying the angioma and the spinal arterial system by which any "steal" could take place.

Although the term "feeding" vessel in these cases of extrathecal AVM is a misnomer, because it is merely the arterialised vein draining away from the angioma on to the cord, it will be employed here because of long usage.

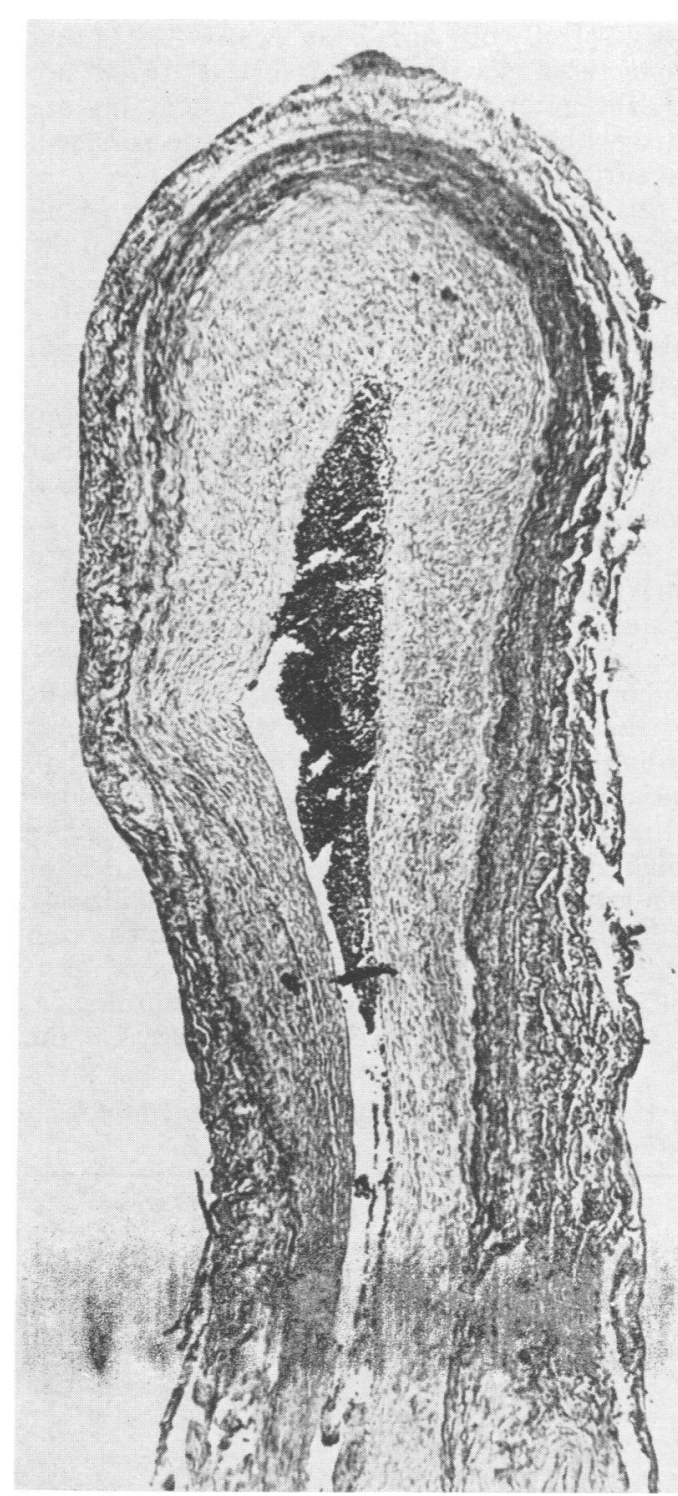

Fig. 3 Transverse section of a portion of the vessel seen in Fig. 2. There is a good deal of collagen in the wall with a thin muscle coat. Strands of elastic tissue are evident but there is no well-formed continuous elastic lamina. Elastic stain, original magnification $\times 100$.

Whether the ultimate destruction of the nerve fibres derives from impaired perfusion and hypoxia due to the raised venous pressure or to the actual compression of the white fibre tracts by the intrinsic distended venules is not clear.

In passing it should be emphasised that the extradural AVM forms only a proportion, at present un- 
specified, of all cord angiomas. Many AVMs that occur in the upper dorsal and cervical region are fed by the anterior spinal arterial system and are situated within the cord, although some possess a dorsal surface component as well.

In this series there were 18 patients from whom representative amounts of vascular tissue from the spinal cord itself were obtained to permit assessment. The consensus of opinion was that the vessels were abnormal veins, no true arterial components being found.

There remain some unanswered questions concerning the venous drainage of the thoracolumbar angiomas. For example, why are the abnormal veins on the back of the spinal cord distended over such a long length (occasionally the entire cord extent) when there are normally eight to twelve large anterior medullary veins and, of more relevance, an even greater number of posterior medullary veins arranged at fairly close intervals along the cord, in fact at every segmental level according to Crock and Yoshizawa (1977), all potentially capable of draining off excess blood into the extradural venous plexus and so reducing the high venous pressure?

This problem is exemplified by the case already described (case 21) in which the dilated vein extended from the termination of the theca up to the T5/6 vertebral level producing neurological signs to the segmental level of T6, whereas if the normal anatomy pertained there would have been three to six anterior and many more posterior medullary veins capable of diverting the abnormal flow. As a corollary to this is the further question as to why, in the case of the extradural AVM, does the venous drainage pierce the theca to attain the cord rather than enter directly into the adjacent extradural venous plexus?

One obvious possibility is that the angioma is a wholly anomalous development with little connection to the normal spinal cord vasculature.

\section{Patients}

This series comprises 24 patients (Table 1), all adults consecutively referred and operated upon, harbouring AVMs situated in the thoraco-lumbosacral cord segments. All were diagnosed by myelography, confirmed by selective arteriography, and treated by direct surgical intervention. In one case only the blood supply was from the anterior spinal artery by a branch winding backwards on to the dorsal aspect of the cord.

Cases treated in earlier years without selective arteriography to demonstrate the feeding vessels have been excluded.

One patient was subjected to percutaneous embolisation of the two vessels of supply with only temporary success, and the angioma was subsequently excised.

Table 1 Age, sex, disability grade, and length of history for gait and sphincter dysfunction before and after operation

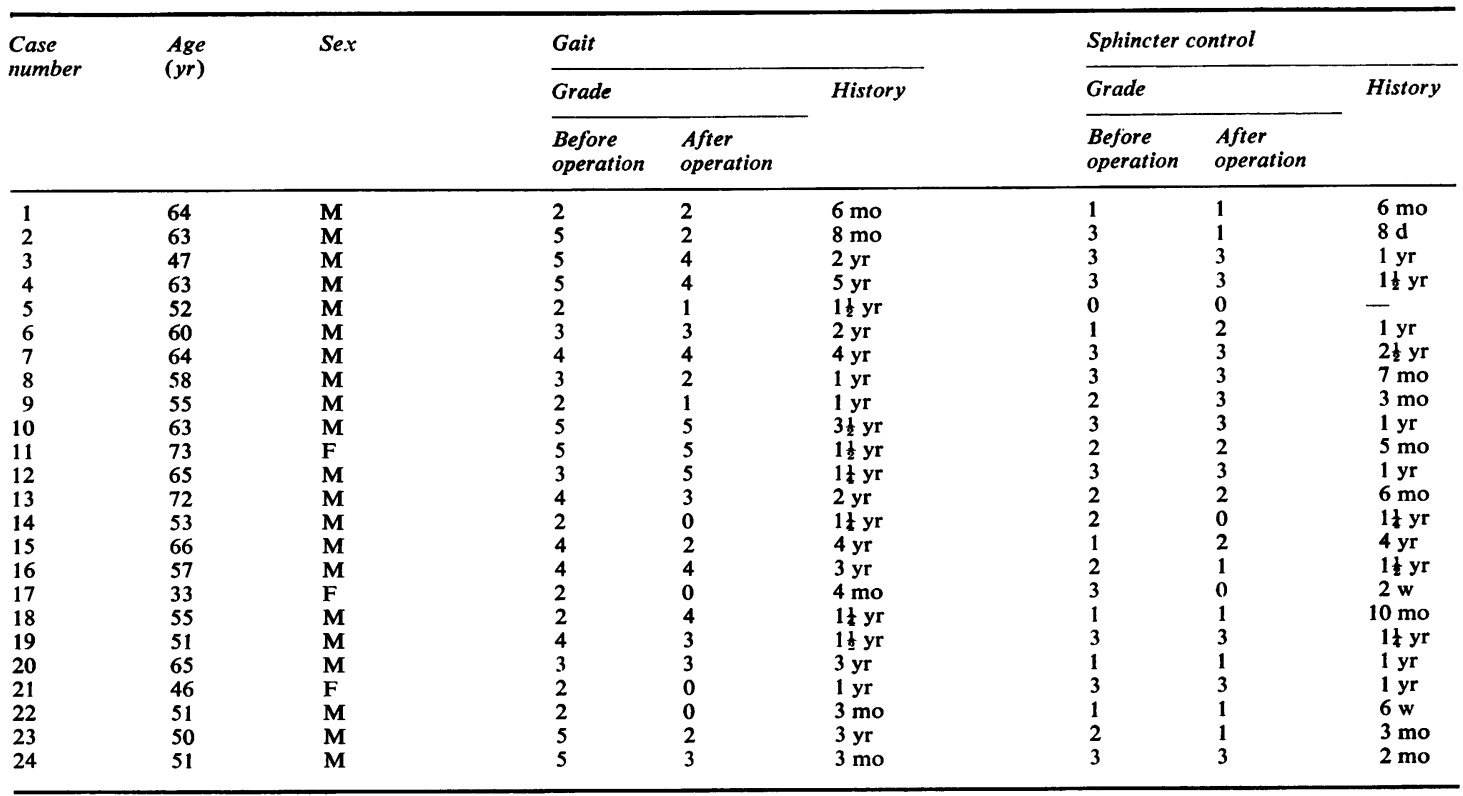




\section{CLINICAL PRESENTATION}

The ratio of 21 men to three women shows an even greater male/female preponderance than that usually recorded for this group of cases (Table 1). Ages ranged from 33 to 73 years with an average of 57.5 years, and the majority, 18 cases, were in the two decades 51 to 70 years.

The presentation of this type of angioma has been included in a previous description (Aminoff and Logue, 1974b), and consists of the gradual onset of progressive and relentless deterioration of spinal function affecting all modalities, but of ten to a disparate degree, sometimes punctuated by episodes of worsening without any signs of intraspinal bleeding and probably caused by spontaneous thrombosis. These incidents occurred in five cases in this series, and in one patient (case 17) clotted vessels in the AVM were confirmed at operation five weeks later. Similar findings have been recorded by others (di Chiro and Wener, 1973; Djindjian, M., 1976).

At the time of surgery every case showed motor weakness of an upper or lower motor neurone type, or both, depending on the spinal cord site, with sensory change, both superficial and deep. Sphincter disturbance, particularly affecting the hladder, occurred in all but one case. Twelve patients complained of pain.

Most of the features which tend to suggest the diagnosis of spinal cord angioma were represented among the 24 patients. These included spontaneous fluctuation in severity taking place over a period of weeks, sometimes of days, in one case of hours, involving some or all modalities; exacerbation of symptoms by walking and relief by rest mimicking intermittent claudication of the cauda equina (five cases), or by the activities of straining or of a bout of coughing. Posture was an aggravating feature in some patients such as standing or sitting up or leaning forward. One case was regularly worse in the evening and better in the morning, and one was made worse on lying down. None, however, showed the symptom of exacerbation after a heavy meal (Oliver et al., 1973). Two patients suffered an inexplicable deterioration after treatment with ACTH, one after a single injection and the other after a course of injections.

\section{Classification of disability}

The pre- and postoperative assessment has been carried out as described previously (Aminoff and Logue, 1974b). The classification relates to functional disability which serves as a practical index and so avoids the analysis of only partly relevant neurological minutiae.

\section{DISTURBANCE OF GAIT}

This is a compound disability deriving from muscle weakness, altered tone or ataxia or both. the latter resulting mainly from loss of proximal joint-position sense in the legs, and is sometimes the most important component.

Disability is divided into five grades: grade 1abnormal stance or gait without restriction of locomotor activity; grade 2-as above but with restricted exercise tolerance; grade 3-requires one stick or some support for walking; grade 4requires crutches or two sticks for walking; grade 5 - unable to walk, confined to bed or wheelchair.

\section{SPHINCTER DISTURBANCE}

Although control of both bowel and bladder was disturbed in all but one patient this was not necessarily to the same degree, and this disparity was particularly evident after operation. Some patients with impaired rectal control may avoid incontinence by remaining costive. Lack of bladder control is more obtrusive and less easy to circumvent and, therefore, bladder function has been used as the index of sphincter disability and is classified into three grades: grade 1-mild-hesitancy, urgency, or frequency; grade 2moderate-as above with occasional incontinence or retention of urine; grade 3-severe-total urinary incontinence or retention.

\section{CUTANEOUS SENSATION}

Every patient had some loss of superficial sensation, affecting all modalities, which ranged in extent from a single dermatome, L5 in one patient (case 5), to areas covering the legs and trunk, often asymmetrically, up to a level as high as the T6 dermatome. The sensory change was usually most marked for pain and temperature.

It was not a major disability to the patient except when it included all modalities subserved by the lower sacral nerves, thus deafferenting the genitalia, urethra, and anal canal, and interfering with sphincter function, or when it was associated with painful paraesthesiae.

PAIN

Twelve patients suffered no or insignificant pain during the course of the disease. In 12 cases there was a complaint of painful symptoms (Table 2).

IMPOTENCE

As most of the 21 men in this group were elderly it was sometimes difficult to judge to what extent the natural aging process influenced the development of impotence.

Sixteen cases provided histories which were 
Table 2 Painful symptoms affecting patients in series

\begin{tabular}{ll}
\hline Symptom & Number of cases \\
\hline Low back pain & 2 \\
Radicular pain round the trunk or down the legs & 5 \\
Paraesthetic pain felt in the limbs in hyperpathic & 3 \\
sensory zones & 2 \\
Painful claudication & 12 \\
Total & 2 \\
\hline
\end{tabular}

sufficiently detailed to permit a reasonably accurate assessment both pre- and postoperatively. In two there was no involvement, but in 14 there was severe impairment or total absence of function. As might be expected there was a relationship between the degree of sphincter involvement and impotence - and of these 14 cases eight were in the grade 3 category of impaired bladder function, three were grade 2 , and three grade 1 .

\section{Investigations}

\section{MYELOGRAPHY}

Myelography, with particular emphasis on supine screening, confirmed the diagnosis in all cases, the tortuous vessels being delineated equally well by Myodil as by water-soluble agents. However, the latter have the advantage that no collections of opaque material remain behind to obscure the details of subsequent arteriography, and they tend to cause less reaction. Several patients developed transiently disturbed bladder function, sometimes necessitating the insertion of a catheter, but there was no case of persistent neurological deterioration.

\section{SELECTIVE ARTERIOGRAPHY}

Selective arteriography was the essential investigation in confirming the presence and extent of the angioma and its feeding vessel(s), and in determining the location of any collateral vessel of supply to the anterior spinal artery in the vicinity, particularly that of Adamkiewicz.

Several patients already suffering from disturbed bladder function developed temporary retention of urine and required catheterisation after arteriography, and some complained of transient exacerbation of leg weakness and sensory loss which recovered in a few days.

Of greater importance were two patients (cases 9 and 12), $8.3 \%$ of the total, who became persistently worse. Patient 9, after a second arteriogram (bilateral subclavian) to exclude a high feeding vessel, experienced deterioration in walking and sphincter control, and declined from grade 2 to grade 3 for each function. Operation was postponed for seven weeks during which time gait improved. It continued to improve after surgery, eventually reaching grade 1 , but incontinence persisted.

Case 12, who before arteriography was rated as grade 3 for both gait and sphincter control, suffered increased weakness of the legs. Operation went ahead six days later but with a poor resultgrade 5 for gait with grade 3 for sphincter control. Although in these two cases there was a previous pattern of steady and fairly rapid neurological deterioration, a serious outcome may also occasionally occur in a patient not previously badly disabled (but not in this series), and cases of virtually complete paraplegia have been known.

The worsening effect in these two cases was confined to the segmental areas already involved and did not extend to a higher level.

\section{Surgical technique}

Elimination of the high venous pressure acting on the spinal cord is the essential requisite of surgery for this group of cases. Before the introduction of selective arteriography the technique of "stripping" the veins of the cord was practised. A long length of vessel was excised, in some cases even the entire extent of the angioma as revealed by myelography. This method certainly did modify or arrest the progression in a number of cases, and this was reported early on by Shepherd (1963), one of the pioneers of surgical treatment, and by Krayenbuhl et al. (1969) and others. This has also been my experience. The degree of success probably depended on the chance proximity of the feeding vessel to the zone of venous removal so that, after operation, the high venous pressure was restricted to a relatively short segment of the cord.

With the currently routine demonstration of the feeding vessel by arteriography the trend has been to interfere with the vessels nearer to the source of inflow. This consists of clipping the "feeder" just after its entry into the theca, either as the sole procedure or combined with "stripping" confined to a few centimetres only of the venous mass, but this latter procedure tends to aggravate posterior column disability.

Since the recognition of the epidural site of a number of these thoracolumbar AVMs (Kendall and Logue, 1977) the technique has again been altered. The small angioma nidus which lies extrathecally on the posterior surface of the root sleeve, and which is attached medially to the theca, is excised with the dural covering of the nerve root (preserving the latter) combined with the small adjacent segment of the theca which surrounds the entry point of the feeding vessel which is 
clipped and divided. There is no "stripping" of the vessels on the cord, a manoeuvre which should reduce the incidence of damage to the posterior columns.

The appearance of the extradural angioma and its relationship to the "feeding" vessel on the cord is shown in Figs. 4a, b, and c, and its pathological features in Fig. 5.
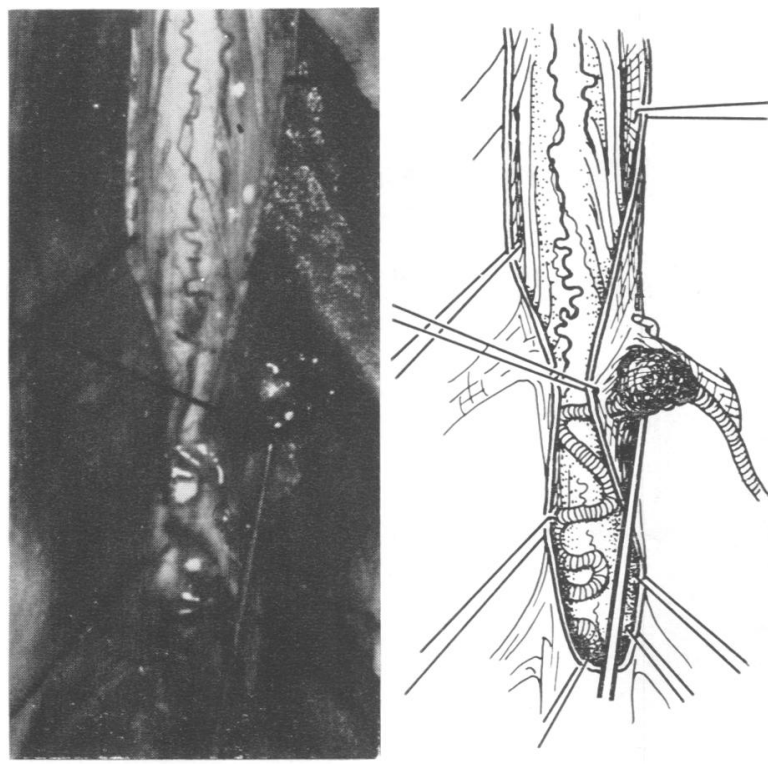

(a)
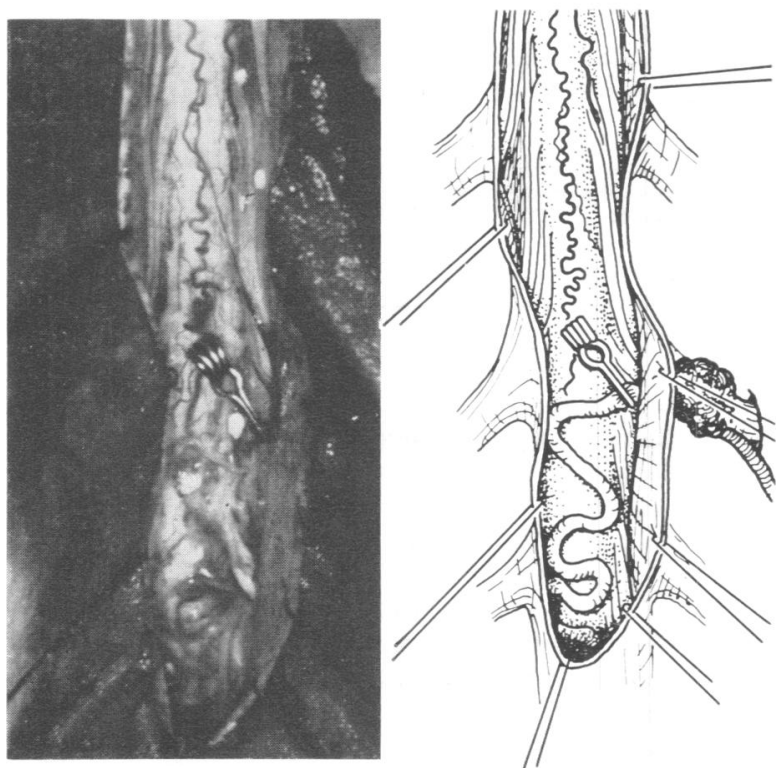

(b)
POSTOPERATIVE ARTERIOGRAPHY

Earlier in this series arteriography was proposed for all cases at about the third postoperative week (Aminoff, 1976), but at present, for those extradural angiomas where complete excision has been effected under direct vision with the operating microscope, it seems unnecessary to subject the patient to the small but definite risk of a further
Fig. 4 (a) An extradural angioma on the right $T 7$ root in a patient too recent to be included in the series. The rounded nidus of vessels forming the $A V M$ on the posterior aspect of the nerve root has been lifted into view by a blunt hook placed in front of the nerve. The incised theca has been retracted over to the left with a stitch. (b) The dura mater has now been retracted to the right and $a$ Scoville clip applied to the "feeding" vessel on the cord which is seen to be partly collapsed. (c) The angioma has been excised with the segment of attached dura mater. Two metal clips have been applied to the intradural vessel and one to the extradural branch of supply from the intercostal artery.
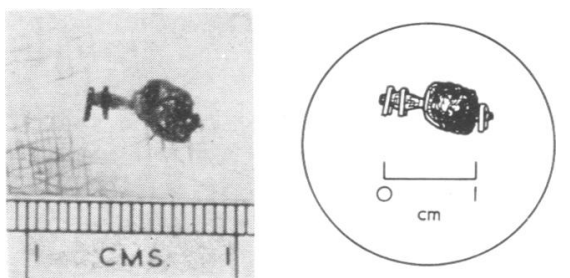

(c) 


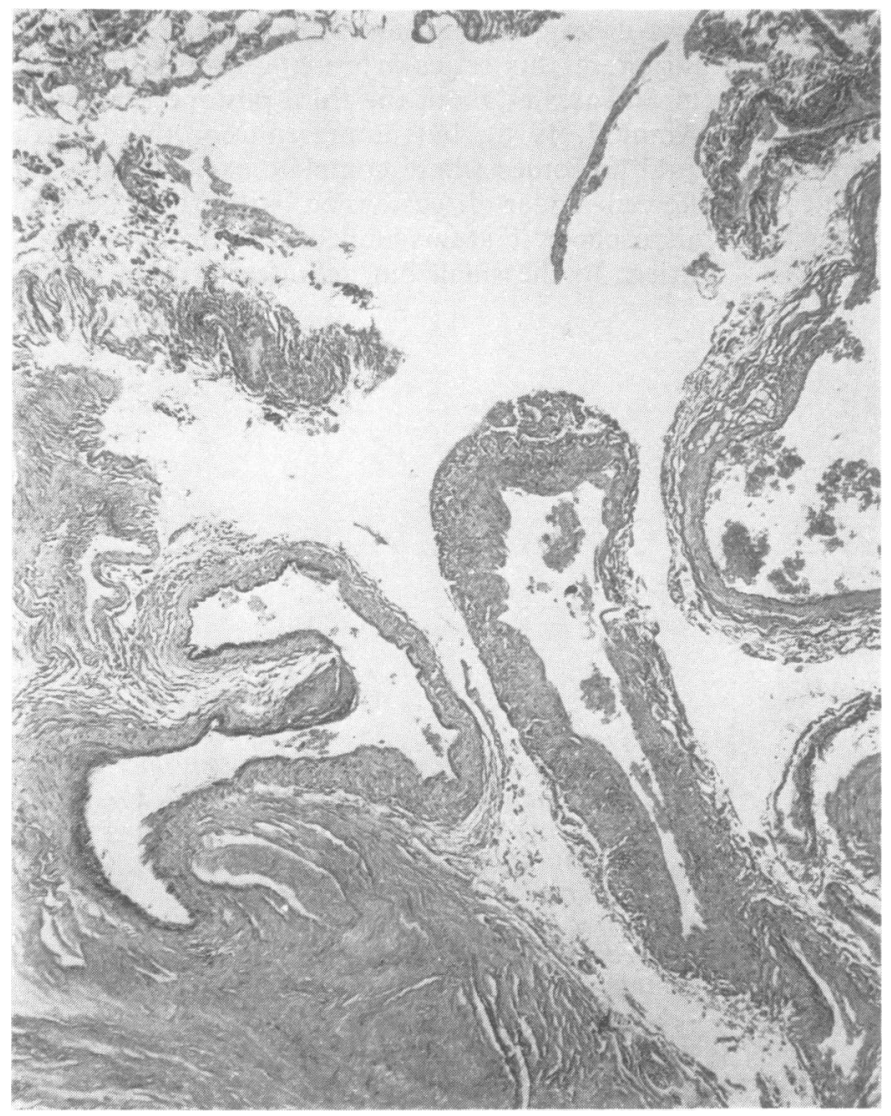

Fig. 5 Photomicrograph of the AVM shown in Fig. 4c to demonstrate abnormal veins and, to the left, an artery with a well-formed elastic lamina.

arteriogram. This latter would still be advisable, however, if there was any doubt concerning the completeness of the excision of the nidus or the presence of additional feeders. It is also essential in those cases where the AVM is not situated extradurally or when deterioration takes place after surgery.

\section{Results}

\section{GAIT}

The assessment of improvement or deterioration in walking ability was recorded in change of grade(s) and was based on the patient's status immediately before surgery which included any alteration resulting from the preliminary investigations (Table 3).

Fifteen patients $(62.5 \%)$ showed some recovery which varied from one grade to a maximum of three grades, and four of these, all grade 2, regained normal walking ability.

Five of the seven chairbound grade 5 patients showed worthwhile improvement-two were able
Table 3 Effect of surgery on walking ability

\begin{tabular}{lc}
\hline Effect of surgery & Number of cases \\
\hline One grade of improvement & 7 \\
Two grades of improvement & 6 \\
Three grades of improvement & 2 \\
Unchanged & 7 \\
Worse & 2 \\
Total & 24 \\
\hline
\end{tabular}

to walk without a stick (grade 2), one walked with one stick (grade 3), and two walked with crutches (grade 4); two remained chairbound.

However, there was no patient of grade 3 status or below who achieved normal walking ability. Seven patients were unchanged.

Two patients, cases 12 and 18 , became worse, deteriorating from grades 3 and 2 to grades 5 and 4 respectively, with no alteration in bladder control. One of these (case 12) started regressing after arteriography. Both had a history of 18 months duration. In both patients the worsening of neurological function started three days after the 
operation and continued, with fluctuations, for three weeks despite maximum steroid and mannitol therapy, when the deterioration stabilised at the new lower level. The most likely explanation of these changes was that of a spreading thrombosis in the small intramedullary vessels.

\section{SPHINCTER DISTURBANCE}

Of the 24 patients only one had previously normal bladder control and underwent surgery uneventfully. Among the remaining 23 cases the results were as shown in Table 4.

Table 4 Effect of surgery on sphincter disturbance

\begin{tabular}{lc}
\hline Effect of surgery & Number of cases \\
\hline One grade of improvement & 2 \\
Two grades of improvement & 2 \\
Three grades of improvement & 1 \\
Unchanged & 15 \\
Worse & 3 \\
Total & 23 \\
\hline
\end{tabular}

Only five $(22 \%)$ of these 23 patients improved, of whom two (cases 14 and 17) regained normal bladder control, starting from grades 2 and 3 with histories of 15 months and two weeks respectively. Among the other three cases one improved two grades, and two improved one grade each.

Fifteen patients $(65 \%)$, of whom nine were grade 3 , remained unchanged.

From the total of 11 grade 3 patients only two improved, one to normal and one to grade 1, their histories being the shortest recorded consisting of eight days and two weeks respectively. Disappointingly, of the six grade 1 cases with bladder dysfunction, four did not show any improvement and two worsened to grade 2 .

Three patients (cases 6, 9, and 15) deteriorated, each worsening by one grade starting from grades 1,2 , and 1 respectively.

\section{SENSATION}

Although ascent or descent of the upper or lower levels of sensory involvement could be recorded fairly accurately, alteration in the quality of sensory change (particularly when comparison was made after a lapse of months or years) was difficult and tended to be unreliable, so that only unequivocal improvement was accepted for tabulation in the postoperative assessment (Table 5).

No patient regained normal sensation, 11 showed modest improvement, in 11 the sensation was unchanged, and in two sensory loss was increased.
Table 5 Effect of surgery on sensation

\begin{tabular}{lc}
\hline Effect of surgery & Number of cases \\
\hline $\begin{array}{l}\text { Change in segmental level } \\
\text { Upper level descended two spinal segments }\end{array}$ & 1 \\
right and left & \\
$\begin{array}{l}\text { Upper level descended three spinal segments } \\
\text { right and left }\end{array}$ & 1 \\
$\begin{array}{l}\text { Upper level descended seven spinal segments } \\
\text { right and left }\end{array}$ & 1 \\
$\begin{array}{l}\text { Upper level descended eight spinal segments } \\
\text { right and left }\end{array}$ & 1 \\
$\begin{array}{l}\text { Upper level descended four spinal segments } \\
\text { right and left, and lower level ascended } \\
\text { five spinal segments right, and nine left }\end{array}$ & 1 \\
$\begin{array}{l}\text { Improvement in quality } \\
\text { Unchanged }\end{array}$ & 6 \\
Worse & 11 \\
Upper level ascended four spinal segments \\
right and left
\end{tabular}

PAIN

Eight of the twelve patients complaining of pain were without pain after operation $(67 \%)$. Painful symptoms which formed a significant component of the overall disability persisted in four cases. In one this was of a radicular type radiating down the leg, and in three it consisted of painful paraesthesiae felt diffusely in the limbs.

\section{IMPOTENCE}

No patient who had lost potency regained it during the time of follow-up (Table 6).

\section{MORTALITY AND FOLLOW-UP}

There were no deaths as a direct result of surgery. One patient (case 12) died five months postoperatively from cardiac failure possibly caused by coronary thrombosis. He was one of the three patients who deteriorated after surgery and made no improvement in the five months from grade 5 gait and grade 3 sphincter status respectively.

Table 6 Effect of surgery on potency in 16 patients

\begin{tabular}{llll}
\hline $\begin{array}{l}\text { Degree of } \\
\text { impairment }\end{array}$ & $\begin{array}{l}\text { Number } \\
\text { of cases }\end{array}$ & $\begin{array}{l}\text { Grade of } \\
\text { associated } \\
\text { sphincter } \\
\text { involvement }\end{array}$ & Postoperative change \\
\hline Full function & 2 & $\begin{array}{l}\text { Grade 0 (1 case) } \\
\text { Grade 1 (1 case) }\end{array}$ & Unchanged \\
$\begin{array}{l}\text { Potency } \\
\text { absent or } \\
\text { severely } \\
\text { impaired }\end{array}$ & 14 & Grade 3 (8 cases) & $\begin{array}{l}\text { Unchanged (4 cases). } \\
\text { Slight but ineffective } \\
\text { improvement (4 cases) }\end{array}$ \\
& Grade 2 (3 cases) & $\begin{array}{l}\text { Unchanged (2 cases). } \\
\text { Slight but ineffective } \\
\text { improvement (1 case) } \\
\text { Unchanged (2 cases). } \\
\text { Slight but ineffective } \\
\text { improvement (1 case) }\end{array}$ \\
\hline
\end{tabular}


The 23 surviving patients have all been followed for a period varying from over eight years to 10 months, a mean of 5.0 years. During that time no patient capable of further deterioration-that is, of grade 4 or above for gait, and grade 2 or above for bladder control-including those who had deteriorated shortly after surgery and then stabilised, has shown any evidence of worsening sufficient to change grades. One patient, case 18, has fluctuated in his grade with regard to gait.

As noted earlier five patients suffered some deterioration, two as a result of arteriography and three from operation.

While one would hesitate to draw firm conclusions from such a limited series of cases certain trends are clear. Operation has been successful in: (1) arresting progression during the period of follow-up of the disease process which would otherwise have proceeded steadily downhill to a virtually complete cord transection; (2) relieving pain of various types in eight out of 12 patients. Painful paraesthetic symptoms have been the least influenced; (3) improving $62.5 \%$ of cases with gait disability but only $22 \%$ of those with impaired bladder control. This latter disparity can only be partly explained by the fewer grades of sphincter dysfunction and this is emphasised by the following observations. In four patients gait returned to normal but only two regained normal bladder control, and these two were common to the former group. Of the seven patients in the lowest category of gait disturbance (grade 5) five showed worthwhile improvement compared with only two of the 11 patients in the lowest category of vesical impairment (grade 3).

\section{Discussion}

These overall results do not engender complacency. However, the series represents in the main a seriously disabled group of patients with a poor prognosis. By the time they came to investigation $12(50 \%)$ of the 24 cases were already in the severely incapacitated groups (4 and 5) with regard to gait, and 11 (nearly $50 \%$ ) were in the most disabled grade (3) of bladder dysfunction.

At the time of surgery the patients with walking disability had histories on average lasting 26 months and those with sphincter disturbance 11.3 months.

The delay in diagnosis was due to several factors. One was because the condition is uncommon (but becoming increasingly recognised), and in the early stages with nonspecific neurological symptoms differential diagnosis covered a wide field. In several cases initial symptoms were attributed to multiple sclerosis. In those with back and leg pain discal disease sometimes leading to operation was diagnosed. For those with early bladder symptoms investigation of prostatic disease was often unduly prolonged. In an age group when cervical spondylosis is rife, cervical myelopathy was sometimes the diagnosis, and treatment with a collar instituted until the inescapable signs of a thoracolumbar lesion appeared. The essential use of myelography was often deferred in an elderly and frail patient until such time as the inexorable downhill march produced serious disability and the mandatory need to exclude a spinal tumour. However, with the water-soluble nonionic agents the discomfort of this test is at present more reduced. In some an early myelogram was carried out but the diagnosis was overlooked because of the lack of supine screening.

Nevertheless the true diagnosis should suggest itself when an elderly male patient develops a thoracolumbar cord syndrome involving all modalities, sensory, motor, and sphincter, often to a varied degree, which follows a progressive downhill course over a few months to a very few years, sometimes with episodic exacerbation. The symptoms may fluctuate in character, and are often aggravated by the striking ambulatory and postural factors mentioned earlier.

Computed tomography, using the whole body scanner as recently reported by di Chiro et al. (1977), may have a part to play in the future as a screening test in the early stage of neurological symptomatology which could then lead on to the definitive investigations.

\section{EMBOLISATION}

In this series all cases were definitively treated by open operation, but percutaneous embolisation of the vessels of supply needs to be considered.

This method has many theoretical merits. It is capable of being performed under the same anaesthetic as the diagnostic arteriogram, it is less traumatic and unpleasant to the patient and, if it should fail, operation can be performed later as occurred with one of the cases in this series. However, doubt has been thrown on its long-term efficacy deriving from the fact that the arteriovenous fistula remains in situ however close to it the embolus impacts in the feeding artery and, unless the lesion thromboses, which is certainly a possibility, it is potentially capable of being revascularised by collateral vessels from the adjacent or contralateral intercostal arteries.

The elegant techniques of R. Djindjian and his colleagues (1975) have elevated embolisation to the status of an art, particularly the selective embolis- 
ing of certain of the intramedullary AVMs supplied from the anterior spinal artery. Their experience with the thoracolumbar angiomas using gelfoam as the embolus has, however, proved disappointing. In 10 cases recently reported (Djindjian, M., 1976) seven were complete failures, and over the longer term analysis it was presumed in a further two of the cases that the method had been ineffective.

At the present time it would seem that embolisation using gelfoam is inferior to surgical excision as far as the thoracolumbar lesions are concerned.

\section{Conclusions}

These surgical results show that the chances of arresting further deterioration are high. However, actual improvement of any significance is mainly in motor power. Pain is helped in about two-thirds of cases but betterment in sphincter control and cutaneous sensation is small and nonexistent with regard to potency.

The essential feature in management is to arrest the progress of the condition by operation, if the patient will accept the relatively small risks, as soon as the pattern and, more importantly, the rate of deterioration becomes manifest, and well before serious disability occurs. For motor power this infers a grade no lower than 2, and for sphincter control certainly no lower than grade 1 but preferably as soon as the first bladder symptoms appear.

This degree of spinal cord dysfunction may occur in a matter of a few months (even within a few weeks) of its inception when treatment becomes a matter of urgency.

Clinical diagnosis in the earlier stages will always remain difficult, but early recourse to myelography with supine screening in a man showing a progressive thoracolumbar cord syndrome will clarify the problem. The reduced morbidity of the nonionic water-soluble contrast agents will make this decision easier.

Surgery for this type of angioma is straightforward presenting little technical difficulty, but any improvement in its results can only come about from earlier diagnosis when, in addition, the angiographic and operative morbidity might be expected to be diminished.

My sincere thanks are due to many former colleagues; the neurologists at The National Hospitals who have referred these cases to me; to Professor L. Duchen at The National Hospital and Dr R. O. Barnard at the Maida Vale Hospital who have given invaluable advice on the neuropathological features; and to the neuroradiologists, Professor Du Boulay, Dr David Sutton, Dr Ivan Moseley, and Dr Brian Kendall who have devoted so much of their time to producing the elegant arteriographic studies which formed the basis for surgery. I am greatly indebted to Mr Prentice in the Department of Medical Illustration at The National Hospital for the photograpiny, and to Mrs Audrey Besterman for the drawings.

\section{References}

Aminoff, M. J. (1976). Spinal Angiomas, p. 132. Blackwell Scientific Publications: Oxford.

Aminoff, M. J., and Logue, V. (1974a). The prognosis of patients with spinal vascular malformations. Brain, 97, 211-218.

Aminoff, M. J., and Logue, V. (1974b). Clinical features of spinal vascular malformations. Brain, 97, 197-210.

Aminoff, M. J., Barnard, R. O., and Logue, V. (1974). The pathophysiology of spinal vascular malformations. Journal of the Neurological Sciences, 23, 255263.

Crock, H. V., and Yoshizawa, H. (1977). The Blood Supply of the Vertebral Column and Spinal Cord in Man, p. 59. Springer-Verlag: New York.

di Chiro, G., and Wener, L. (1973). Angiography of the spinal cord. Journal of Neurosurgery, 39, 1-29.

di Chiro, G., Doppman, J. L., and Wener, L. (1977). Computed tomography of spinal cord arterio-venous malformations. Radiology, 123, 351-354.

Djindjian, M. (1976). Les malformations arterioveineuses de la moelle epinière et leur traitement. Thesis for doctorate in medicine. University of Paris.

Djindjian, R. (1975). Embolisation of angiomas of the spinal cord. Surgical Neurology, 4, 411-420.

Heindel, C. C., Dugger, G. S., and Guinto, F. C. (1975). Spinal arterio-venous malformations with hypogastric blood supply. Journal of Neurosurgery, 42, 462-464.

Kendall, B. E., and Logue, V. (1977). Spinal epidural angiomatous malformations draining into intrathecal veins. Neuroradiology, 13, 181-189.

Krayenbuhl, H., Yasargil, M. G., and McClintock, H. G. (1969). Treatment of spinal cord vascular malformations by surgical excision. Journal of Neurosurgery, 30, 427-438.

Oliver, A. D., Wilson, C. B., and Boldrey, E. B. (1973). Transient post-prandial paresis associated with arterio-venous malformations of the spinal cord. Journal of Neurosurgery, 39, 652-655.

Shepherd, R. H. (1963). Observations on intradural spinal angiomas. Neurochirurgica, 6, 58-74.

Stein, S. C., Ommaya, A. K., Doppman, J. L., and di Chiro, G. (1972). Arterio-venous malformations of the cauda equina with arterial supply from branches of the internal iliac arteries. Journal of Neurosurgery, 36, 649-651. 